\title{
Emergence to Develop an Appraisal System for Agricultural Practices in Malaysia
}

\author{
Md. Wahid Murad", Chamhuri Siwar', Nik Hashim Nik Mustapha, Nik Fuad Nik Mohd. Kamil, \\ Suriyani Muhamad, and Azlina Abdul Aziz \\ Department of Economics, Faculty of Management and Economics, University of Malaysia \\ Terengganu (UMT), 21030 Kuala Terengganu, Malaysia \\ 1. Institute for Environment and Development (LESTARI), National University of Malaysia, \\ 43600 UKM Bangi, Selangor Darul Ehsan, Malaysia
}

KEYWORDS Agricultural Sustainability. Environmental Problems. Agricultural Production Index. Food Production Index. Fertilizer Nutrients Consumption. Area of Arable and Permanent Crops. Value Added by Agriculture

\begin{abstract}
This study is an effort to justify an emergence to develop an appraisal system for agricultural practices in Malaysia. The idea has come from the fact that although the policies for promoting Malaysia's agriculture sector towards sustainability were endorsed in 1998, but some agricultural practices in the country are found to be connected with environmental problems. Advanced quantitative analytical tools such as stationary tests and least squares estimations have been employed to attain the study objective and justify our arguments. The results, however, reveal that agricultural practices in Malaysia have been connected, to some extent, with environmental problems in the country. An increase in fertilizer consumption has been found to be positively connected with both agricultural production index and food production index for the country. The study also found that the contribution of Malaysian agriculture in terms of its value added to the national economy is certainly creditable, but this could have been connected with environmental problems on a greater scale. The results further reveal that an increase in the area of arable and permanent crops has also been associated with higher agricultural production index and food production index for the country. While most agricultural practices in Malaysia are observed to have been generally compatible with the standards of sustainable agriculture, an emergence still arises for the country to develop an appraisal system for monitoring its current agricultural practices. It is expected that the development of such an appraisal system will enable Malaysia to transform its agriculture into sustainable in which agricultural resources will not be exploited and environmental degradation will be absent.
\end{abstract}

\section{INTRODUCTION}

Agriculture sector in Malaysia has been playing an important role in livelihood and economic development of the country. Malaysia has 4.06 million hectares of agricultural land distributed throughout 13 states. Eighty percent of this land is cultivated with industrial crops such as palm oil, rubber, cocoa, coconut, and pepper. Over the last few years the agriculture sector contributed significantly to gross domestic product (GDP) and it became the third engine of growth next to the manufacturing sector and service sector. Since 1980s, one of the major challenges experienced by Malaysia's agriculture sector is the land problem as agricultural land was taken over for industrial, infrastructural, and housing purposes. There was also less market protection for agriculture sector as it enjoyed very

${ }^{*}$ Corresponding author:

Telephone: +6096684152 ,

Fax: +60 9668 4237,

E-mail: mwmurad@gmail.com little in contrast to the manufacturing sector. Export taxes have been imposed on palm oil, rubber and pepper, and agricultural production had declined as the result. On the other hand, trade protection for manufacturing sector enhanced the credit worthiness enabling manufacturing sector to obtain financing easily. While the manufacturing sector was enjoying such advantages it was not difficult to observe why there had been a persistent outflow of resources from agricultural sector to manufacturing sector, thus exploiting agricultural growth.

The Ministry of Agriculture, Malaysia, however, had taken the First National Agricultural Policy in 1984 and the Second National Agricultural Policy in 1992 with the view to maximize income from agriculture sector through efficient utilization of domestic resources and recovery of the sector's contribution to the overall economic development of the country. The emphasis was given on the increase of farms' productivity by choosing remunerative crops and employing the most efficient technologies. 
Observations reveal that the First National Agricultural Policy was failed to look into increasing income and productivity disparity between the agriculture sector and the rest of the economy, especially the manufacturing sector. It is worth noting to mention that implementation of the first and second national agricultural policies since 1984 has enabled the agricultural sector to attain a growth rate of 3.2 percent per annum for the period from 1985 to 1995 . The strategies taken under these two agricultural policies deserve good merit due to the fact, among others, that during the period of these two policies the authorities developed new agricultural land to enable the establishment of new economic farm units. Efficient agricultural practices have been fostered and land has been provided to agricultural farmers for growing new crops. Institutional development of land was also carried out in order to resolve the problems of uneconomic farm sizes, uneconomical crops, and low levels of productivity. Agricultural support services such as research, extension, marketing, fiscal incentives, and social and institutional development were also provided by the Ministry of Agriculture.

Upon realizing some shortfalls and inefficiencies of the agricultural sector, however, the Second National Agricultural Policy (1992-1997) was revised in 1998 and subsequently the Third National Agricultural Policy (1998-2010) was introduced. This new agricultural policy was founded on a vision of sustainable development of a dynamic agriculture sector in the way that the growth of agriculture was to be market-led, commercialized, efficient, and competitive. Still with the principal aim of maximizing income through optimal utilization of resources, the major objectives of this new policy are: (a) to achieve a balanced development between agriculture and the other sectors of the economy; (b) to enhance the economic/structural integration of the sector with the rest of the economy, and in particular with the manufacturing sector; (c) to achieve a higher level of expansion and development of the food industry sub sector; (d) to achieve a wider and more effective representation and participation of the Bumiputra (indigenous) community in modern and commercial agriculture, agribusiness, and agricultural trade; and (e) to ensure sustainable development in agriculture. Under the Third National Agricultural Policy efforts to enhance productivity have also been taken through the utilization of high yielding crops and improvements in agronomic practices among smallholders and plantations as well as increased mechanization. In addition, the provision of adequate support services and infrastructure in the agricultural production areas was emphasized to further improve productivity in the sector. It was also envisaged under this policy that productivity will be increased through wider application of the latest technology and knowledge-based production systems.

However, agriculture sector has a profound impact on both the environment and people of the country. What happens in the agriculture sector is not only an economic issue; it also has important biological, environmental, social, cultural, and ethical aspects for the country. New scientific knowledge coupled with concerns for the economical, environmental, and social aspects of agriculture have brought Malaysian agriculture into a state of transition. Market pressures at home and abroad, costs of production, and concern for food security have prompted the country to producing food and fiber in the way that is considered unsustainable to some extent. Consequently, an emergence has arisen for Malaysia to develop an appraisal system for monitoring its agricultural practices, which are found to have been connected with some environmental problems in the country. This study is an effort to examine whether or not the agricultural practices in Malaysia are, to some extent, linked with environmental degradation in the country.

\section{BRIEF LITERATURE REVIEW}

The Swedish Society for Nature Conservation (1999) quoted "We should not allow ourselves to produce and consume our food at the expense of people and ecosystems in other parts of the world. Farming in the world is interlinked via trade of both inputs and outputs. If we consumers purchase environmentally damaging products, we are contributing to environmental pollution and depletion, even though it may occur in other parts of the world. The environmental problems connected with Malaysian agriculture sector have been sketched by some researchers. In recent years, as a result of growing concern on health hazards posed by chemical fertilizers used by the agricultural farmers in Malaysia, there is now a concerted effort to review the use of these 
fertilizers and to place more emphasis on the use of organic fertilizers (Ahmad, F. 2001). Studies reveal that the modernization of agriculture has come about with increased fertilizer consumption. In Southeast Asia, fertilizer consumption increased 122 percent, contributed by the high consumption rates in some countries like Vietnam, Thailand, and Malaysia (United Nations Development Program 2001). The same study also reveals that Malaysia alone recorded a more growth rate of 324 percent between 1970 and 1998 . The general increase over 29-year period is certainly a very notable feature of Malaysian agriculture. Together with the heavy use of herbicides and pesticides, this chemical utilization indicates major changes in farming practice and causes for serious concern due to the environmental consequences.

It is worthwhile to mention here that Malaysia still does not have self sufficiency in many food items due to lack of comparative advantage in food production. By comparative advantage, it is cheaper to import food from neighboring countries than to produce them in Malaysia (Ahmad, F. 2001). In fact, increase in price of imported foods from other countries has also caused Malaysia to experience an outflow of a significant amount of foreign currencies in the recent years. The food bill has increased from MYR3.5 billion in 1985 to MYR11.3 billion in 2000 and it is still increasing (Department of Statistics 2001). This has caused tremendous strain on the economy due to lost of foreign exchange, the attendant ill-effect brought about by inflation (Ahmad F 2001). The changing needs in the economy in particular are acute labor shortage, limited availability of suitable land, increasing cost of production, decline in the exchange rates, the establishment of World Trade Organization (WTO) and the rapid liberalization of agricultural trade, which have brought new issues and challenges in Malaysian agricultural sector (Ahmad F 2001).

In view of the above challenges, however, the Third National Agricultural Policy (1998-2010) was endorsed with the overriding objective of maximizing income through the optimal utilization of resources in the sector. The specific objectives of the policy are to enhance food security; to increase productivity and competitiveness of the sector; to deepen linkages with other sectors; to create new sources of growth for the sector; and to conserve and utilize natural resources in a sustainable basis (Ministry of Agriculture 1998).
In Malaysia, although smallholders' contribution in agriculture sector is significant, they comprise of the bulk of low income groups in the country and suffer the most due to uneconomic land size, price decline in commodities like rubber, cocoa and oil palm, rising production cost and persistent low productivity and income (Ahmad F 2001). The area of agricultural land in Malaysia is also decreasing. In conventional rubber planting, 85 percent of the exposed areas is drastically reduced to 45 percent in second year and completely covered at the end of third year (Ghani and Zulkefly 2001). The situation of organic food production is also not good in Malaysia. Since chemical fertilizers and pesticides are not used, labor requirement is high in organic farming leading to high cost of production (Ahmad F 2001). If organic foods can be sold at competitive prices, higher to some degree but not too much higher than non-organic products, then there would be a market and demand-driven basis for the food sector to be based increasingly on sustainable agriculture.

In recent years, as a result of increasing awareness on health and environment issues, systematic programs have been introduced by the Ministry of Agriculture to optimize the use of resources on a sustainable basis including the recycling of waste products for food production and environment protection (Ahmad F 2001). The Department of Agriculture had launched the Good Agricultural Practice (GAP) scheme on $31^{\text {st }}$ January 2002 to promote some of the sustainable agricultural practices. Since it was a voluntary scheme the majority of the farm holders were reluctant to comply with the GAP guidelines. In the context of efficient land use, which is the element of soil and water conservation, much need to be done to ensure the prolonged use of the land on a sustainable basis (Ahmad F 2001). Whether the nation achieves the sustained agricultural productivity growth in the coming years will depend on the current policies that are being planned and implemented (Shamsudin et al. 1999).

\section{MATERIALS AND METHODS}

In order to test the hypothesis and attain objectives this study has used multiplicity of econometric techniques. The data for this study have been gathered from two sources, which include the United Nations' online data base 
(http://data.un.org/) and the Food and Agriculture Organization's online data base (http:// faostat.fao.org/). However, with available data obtained from the above two sources we have examined the following three agricultural sustainability issues for Malaysia: (1) Exploitation of agricultural resources, (2) Environmental degradation due to existing agricultural practices, and (3) Economic expansion due to existing agricultural activities.

We must admit that all the necessary variables for examining the above three issues were not considered in the present study due to lack of relevant data. Thus we have considered only five important variables to materialize our objective and substantiate our arguments. The variables that have been considered in the study are: (1) Agricultural production index (which is coded as AGRICPI), (2) Food production index (which is coded as FPI), (3) Value added by agriculture, hunting, and forestry at current prices (MYR) (which is coded as VAAHF), (4) Area of arable and permanent crops in thousand per hectares (which is coded as AAPC), and (5) Total fertilizer nutrients consumption in thousand tones (which is coded as TFNC). Worth noting to mention here that the data for all the above five variables were found available from year 1989 to year 2007 with a little discontinuation. The data discontinuity, however, has been solved by replacing data with their proportional values calculated by applying percent change formula to the data before and after a missing value. The Augmented DickeyFuller (ADF) test has thus been used to check whether gathered data series are stationary or non stationary in nature. With results obtained from ADF test we were then guided to apply the Least Squares method. Subsequently, some other econometric tools such as Jarque-Bera test, Breusch-Godfery Serial Correlation LM test, and Breusch-Pagan-Godfery Heteroskedasticity test have been applied to check the model residuals and to examine the strength of the model. All the above analysis has been conducted using the Eviews software with version 6.0.

\section{RESULTSAND DISCUSSIONS}

\section{Stationary Tests}

At the first stage of data analysis we have applied ADF test to check whether the data series are stationary or non-stationary in nature. Before applying this test for all the variables/series we have transformed the data into the following three stages of fundamental regression equations:

(1) $\Delta \mathrm{Y}_{\mathrm{t}}=\delta \mathrm{Y}_{\mathrm{t}-1}+\mathrm{u}_{\mathrm{t}}$ (without constant and trend)

(2) $\Delta Y_{t}^{t}=\alpha+\delta Y_{t-1}+u_{t}$ (with constant), and

(3) $\Delta \mathrm{Y}_{\mathrm{t}}=\alpha+\beta \mathrm{T}+\delta \mathrm{Y}_{\mathrm{t}-1}+\mathrm{u}_{\mathrm{t}}$ (with constant and trend).

The ADF unit root test hypothesis that was applied to above three regression equations is:

Ho : $\delta=0$ (Unit Root)

Ha : $\delta \neq 0$

While considered the variable of agricultural production index (AGRICPI), for example, the above three stages of equations take the following transformed norms, respectively:

(4) $\triangle$ AGRICPI $_{\mathrm{t}}=\delta$ AGRICPI $\mathrm{t}_{\mathrm{t}-1}+\mathrm{u}_{\mathrm{t}}$ (Without constant and trend)

(5) $\Delta$ AGRICPI $_{\mathrm{t}}=\alpha+\delta$ AGRICPI $_{\mathrm{t}-1}+\mathrm{u}_{\mathrm{t}}$ (With Constant), and

(6) $\Delta$ AGRICPI $_{\mathrm{t}}=\alpha+\beta \mathrm{T}+\delta$ AGRICPI $_{\mathrm{t}-1}+\mathrm{u}_{\mathrm{t}}$ (With Constant and Trend).

Similarly, transformations have also been done for the rest four variables. The ADF test results, however, reveal that only one data series, namely area of arable and permanent crops in thousand per hectares (AAPC) is stationary and that we can reject the null hypothesis for this series (Table 1). This is because the ADF test statistics for this variable is found to be smaller than the critical tvalues at $1 \%, 5 \%$, and $10 \%$ significant levels. The rest four data series for variables, namely agricultural production index (AGRICPI), food production index (FPI), value added by agriculture, hunting and forestry at current prices (MYR) (VAAHF), and total fertilizer nutrients consumption in thousand tones (TFNC) are all found to be nonstationary as the ADF test statistics for all these variables are found to be greater than the critical tvalues at $1 \%, 5 \%$, and $10 \%$ significant levels and hence we can accept the respective null hypotheses. Even though the Durbin-Watson statistics for all six variables were found to be considerably high, which simply confirms reliability and no autocorrelation problem in the subset of data, the combination of both stationary and nonstationary natures of data eventually prompted us to apply the Least Squares method.

\section{Least Squares Estimation for Agricultural Practices in View of Sustainability}

At the outset of Least Squares Estimation the determination of both endogenous and 
exogenous variables was done. Two endogenous variables have been selected and regressed them separately against three other exogenous variables. For example, the endogenous variable of agricultural production index (AGRICPI) was regressed against three exogenous variables such as area of arable and permanent crops in thousand per hectares (AAPC), fertilizer nutrients consumption in thousand tones (TFNC), and value added by agriculture, hunting and forestry at current prices (MYR) (VAAHF). The Least Squares estimation, however, produced the following equation for AGRICPI and the estimation summary is shown in Table 2:

AGRICPI $=-63.156259702+0.01377945$ 94898*AAPC + 2.28764023614e-05*TFNC + $1.04510339332 \mathrm{e}-09 * \mathrm{VAAHF}$ (1)

The estimated equation 1 shows that the exogenous variables namely area of arable and permanent crops in thousand per hectares (AAPC), fertilizer nutrients consumption in thousand tones (TFNC), and value added by agriculture, hunting and forestry at current prices (MYR) (VAAHF) are all positively linked with the endogenous variable of agricultural production index (AGRICPI). This simply means, assuming other factors remain constant, that Malaysia has had continually enjoyed higher agricultural production over the period from 1989 to 2007 due to an increase in the above three agricultural inputs. Table 2 reveals that only one exogenous variable, namely VAAHF is significant at $5 \%$ $(\mathrm{P}<0.05)$ while other two exogenous variables (AAPC and TFNC) are insignificant as the probability values for these two variables exceed $10 \%$ confidence level $(\mathrm{P}>0.1)$. An increase in value added by the agriculture sector to the Malaysian national output is certainly praiseworthy while an increase in the area of arable and permanent crops as contributing positively to the national economy is also laudable. But the positive relationship between total fertilizer nutrients consumption (TFNC) and agricultural production index (AGRICPI) for Malaysia is undoubtedly alarming as such practice runs against the standards of sustainable agriculture. Even though the relationship is not statistically significant, but a high adjusted $\mathrm{R}^{2}$ value $(0.84)$ demonstrates the strength of such finding and the model itself.

In order to validate the strength of the above model some residual tests have also been conducted. For example, Jarque-Bera test produced

Table 1: Summary of Stationary Tests.

\begin{tabular}{lcccllll}
\hline \multirow{2}{*}{$\begin{array}{l}\text { Variablel } \\
\text { Series }\end{array}$} & $\begin{array}{c}A D F \\
\text { Statistics }\end{array}$ & \multicolumn{2}{c}{ t-Statistics (Test Critical Values) } & \multirow{2}{*}{$\begin{array}{l}\text { Decision } \\
\text { Watson Stat. }\end{array}$} & Durbin- & \multirow{2}{*}{ Prob. } \\
\cline { 3 - 5 } & & 1\% Level & $5 \%$ Level & 10\% Level & & & \\
\hline AGRICPI & -0.977261 & -4.57 & -3.69 & -3.29 & Non-Stationary & 2.32 & 0.9221 \\
FPI & -1.912829 & -4.57 & -3.69 & -3.29 & Non-Stationary & 2.27 & 0.6065 \\
AAPC & -6.048099 & -4.57 & -3.69 & -3.29 & Stationary & 1.49 & 0.0007 \\
TFNC & -1.973128 & -4.57 & -3.69 & -3.29 & Non-Stationary & 1.82 & 0.5760 \\
VAAHF & -0.287158 & -4.57 & -3.69 & -3.29 & Non-Stationary & 1.57 & 0.9967 \\
\hline
\end{tabular}

Table 2: Summary of Least Squares Estimation when Agricultural Production Index (AGRICPI) is the Endogenous Variable.

Dependent Variable: AGRICPI

Method: Least Squares

Sample: 19892007

Included observations: 19

\begin{tabular}{lclcc}
\hline & Coefficient & Std. Error & t-Statistic & Prob. \\
\hline C & -63.15626 & 57.20139 & -1.104104 & 0.2869 \\
AAPC & 0.013779 & 0.008177 & 1.685201 & 0.1126 \\
TFNC & $2.29 \mathrm{E}-05$ & $2.06 \mathrm{E}-05$ & 1.113162 & 0.2832 \\
VAAHF & $1.05 \mathrm{E}-09$ & $4.77 \mathrm{E}-10$ & 2.188948 & 0.0448 \\
R-squared & 0.864747 & Mean dependent var & & 98.04737 \\
Adjusted R-squared & 0.837696 & S.D. dependent var & & 19.20585 \\
S.E. of regression & 7.737451 & Akaike info criterion & & 7.114686 \\
Sum squared resid & 898.0223 & Schwarz criterion & & 7.313515 \\
Log likelihood & -63.58951 & Hannan-Quinn criter. & & 7.148335 \\
F-statistic & 31.96772 & Durbin-Watson stat & & 1.146856 \\
Prob(F-statistic) & 0.000001 & & & \\
\hline
\end{tabular}


a statistical value of 2.451566 , which is not statistically significant $(\mathrm{P}>0.1)$. So we can conclude that the time series data that have been considered in the model were normally distributed. Next, Breusch-Godfrey Serial Correlation LM Test was also conducted to check the model residuals. This test, however, produced a value for F-statistic (2.209782), which was found to be statistically insignificant $(\mathrm{P}>0.1)$. Thus, it can be concluded that there was no serial correlation problem in the above model. Breusch-Pagan-Godfrey Heteroskedasticity Test was conducted to check the model residuals finally. The test produced a value for F-statistic (0.826627), which was also found to be statistically insignificant $(\mathrm{P}>0.1)$. Therefore, it can also be concluded that the model that has been developed above does not have any Heteroskedasticity problems.

It has been mentioned earlier that two endogenous variables were selected and both they have been regressed against three particular exogenous variables. Since, the endogenous variable of agricultural production index (AGRICPI) has already been regressed against those exogenous variables, the Least Squares estimation has now been used to regress the other endogenous variable, namely food production index (FPI). The justification for using both AGRICPI and FPI as the endogenous variables arises due to the fact that agricultural production and food production are significantly different one from other. While an agricultural production index for a particular year shows the relative level of the aggregate volume of agricultural production for that year in comparison with the base period, the food production index has a bit different meaning. This is because all the agricultural outputs are not food and thus food production index means something not fully consistent with the meanings of agricultural production index. A food production index for a particular year reasonably shows the relative level of the aggregate volume of food production for that year in comparison with the base period. Even though both indices certainly complement one to other, the difference has already been evident from the above discussion. Therefore, beside AGRICPI as the endogenous variable the FPI has also been regressed against those exogenous variables of area of arable and permanent crops in thousand per hectares (AAPC), fertilizer nutrients consumption in thousand tones (TFNC), and value added by agriculture, hunting and forestry at current prices (MYR) (VAAHF). The Least Squares estimation, however, produced the following equation for FPI and the estimation summary is shown in Table 3:

$\mathrm{FPI}=-115.750655687+0.0204105884122 *$ $\mathrm{AAPC}+2.35463732208 \mathrm{e}-05^{*} \mathrm{TFNC}+1.045200$ 60022e-09*VAAHF

The above equation shows that the exogenous variables namely area of arable and permanent crops in thousand per hectares (AAPC), fertilizer nutrients consumption in thousand tones (TFNC), and value added by agriculture, hunting and forestry at current prices (MYR) (VAAHF) are all positively linked with the endogenous variable, namely food production index (FPI). This just implies, assuming other factors remain constant, that Malaysia has had continually enjoyed higher food production in the country over the period from 1989 to 2007

Table 3: Summary of Least Squares Estimation when Food Production Index (FPI) is the Endogenous Variable.

Dependent Variable: FPI

Method: Least Squares

Sample: 19892007

Included observations: 19

\begin{tabular}{lclcc}
\hline & Coefficient & Std. Error & $t$-Statistic & Prob. \\
\hline C & -115.7507 & 63.09978 & -1.834407 & 0.0865 \\
AAPC & 0.020411 & 0.009020 & 2.262840 & 0.0389 \\
TFNC & $2.35 \mathrm{E}-05$ & $2.27 \mathrm{E}-05$ & 1.038660 & 0.3154 \\
VAAHF & $1.05 \mathrm{E}-09$ & $5.27 \mathrm{E}-10$ & 1.984516 & 0.0658 \\
R-squared & 0.857407 & Mean dependent var & 95.88947 & \\
Adjusted R-squared & 0.828888 & S.D. dependent var & 20.63382 & \\
S.E. of regression & 8.535308 & Akaike info criterion & 7.310964 & \\
Sum squared resid & 1092.772 & Schwarz criterion & 7.509793 & \\
Log likelihood & -65.45416 & Hannan-Quinn criter. & 7.344614 & \\
F-statistic & 30.06485 & Durbin-Watson stat & 1.095252 & \\
Prob(F-statistic) & 0.000001 & & & \\
\hline
\end{tabular}


due to an increase in the above three exogenous agricultural inputs. Table 3 reveals that the exogenous variable, namely total fertilizer nutrients consumption in thousand tones (TFNC) is not statistically significant $(\mathrm{P}>0.1)$ while other two exogenous agricultural inputs, namely area of arable and permanent crops in thousand per hectares (AAPC) and value added by agriculture, hunting and forestry at current prices (MYR) (VAAHF) are statistically significant at 5\% $(\mathrm{P}<0.05)$ and $10 \%(\mathrm{P}>0.05)$ levels, respectively. Indeed, an increase in the area of arable and permanent crops as contributing positively to the national food production is commendable. As expected an increase in the value added by the Malaysian agriculture sector to its food production is admirable. But the positive relationship between total fertilizer nutrients consumption (TFNC) and food production index (FPI) for the country is unquestionably upsetting as the practice of producing foods using augmented fertilizer nutrients contradicts with the broad standards of sustainable agriculture. While considered the TFNC as an exogenous agricultural input in the Least Squares estimation it produced an insignificant probability value ( $\mathrm{P}>0.01)$. On the whole, the model has generated a high adjusted $\mathrm{R}^{2}$ value $(0.83)$ and thus confirms the strength of finding and the model itself.

In a similar way, the residual tests have been conducted to validate the strength of the above model. At the first of such stage, Jarque-Bera test produced a statistical value of 0.629392 and a probability value of 0.73 , which is not statistically significant $(\mathrm{P}>0.1)$. Accordingly, we can conclude that the agricultural time series data that have been used in the model were normally distributed. At the second stage, Breusch-Godfrey Serial Correlation LM Test was conducted to check the model residuals. This test, however, produced a value for F-statistic (2.793041) which was found to be statistically significant only at $10 \%$ level $(\mathrm{P}<0.1)$. This implies that there was, to some extent, a serial correlation problem in the above model. If we just stick to the highly acceptable significant levels of $1 \%$ and $5 \%$ the problem of serial correlation in the model could easily be avoided. Finally, the Breusch-Pagan-Godfrey Heteroskedasticity Test was conducted to check the model residuals. The test, however, produced an F-statistic value of 0.765172 , which was found to be statistically insignificant $(\mathrm{P}>0.1)$. Consequently, it can be concluded here that the above model does not have any Heteroskedasticity problems.

\section{CONCLUSION}

It has been evident that agricultural practices in Malaysia have been connected, to some extent, with environmental problems in the country. An increase in fertilizer consumption has been found to be positively connected with both agricultural production index and food production index for the country. Contribution of Malaysian agriculture in terms of its value added to the national economy is certainly creditable, but this could also be connected with environmental problems on a greater scale. An increase in the area of arable and permanent crops has also been associated with higher agricultural production index and food production index for the country. This is due to the fact that Malaysia has been expanding its agricultural land by cultivating the lands that were previously either abandoned or not suitable for farming. The country, however, has had taken substantial efforts to transform its agriculture into sustainable. While most agricultural practices in Malaysia are generally compatible with the standards of sustainable agriculture, an emergence thus arises for the country to develop an appraisal system for closely monitoring its current agricultural practices. Thus, it is expected that development of such an appraisal system will enable Malaysia to transform its agriculture into practically sustainable in which agricultural resources will not be exploited and environmental degradation will be absent.

\section{REFERENCES}

Ahmad F 2001. Sustainable agriculture system in Malaysia. Paper presented at Regional Workshop on Integrated Plant Nutrition System (IPNS), Development in Rural Poverty Alleviation. United Nations Conference Complex, Bangkok, Thailand, September 18 to 20, 2001.

Department of Statistics 2001. Monthly Statistical Bulletin 2001 (November Issue). Kuala Lumpur: Department of Statistics.

Ghani A, Zulkefly S 2001. Maximizing land use under rubber production. Paper presented at Malaysian Soil Science Society Seminar. Kota Kinabalu, Sabah, Malaysia, April 17 to 20, 2001.

Ministry of Agriculture 1998. Third National Agricultural Policy 1998-2010. Kuala Lumpur: Ministry of Agriculture.

Official Home Page of Food and Agriculture Organization 2009. FAO Statistics (FAOSTAT). From <http:// faostat.fao.org> (Retrieved June 14, 2009).

Official Home Page of United Nations 2009. UN Data A World of Information. From <http://data.un.org/ Default.aspx> (Retrieved June 14, 2009). 
Shamsudin MN, Radam A, Abd Latif I 1999. Productivity in the Malaysian agriculture sector: Status and policy options to increase productivity. Paper presented at the National Seminar on Repositioning the Agriculture Industry in the Next Millennium. Department of Agribusiness and Information System, Faculty of Agriculture, Universiti Putra Malaysia, July 13 to 14, 1999.
Swedish Society for Nature Conservation 1999. Policy for Sustainable Agriculture. Stockholm: Birger Gustafsson AB.

United Nations Development Program 2001. Partnerships to Fight Poverty. New York: United Nations Development Program. 